\title{
GPS TEC, scintillation and cycle slips observed at high latitudes during solar minimum
}

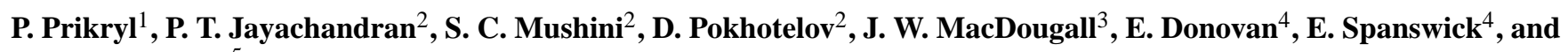 \\ J.-P. St.-Maurice ${ }^{5}$ \\ ${ }^{1}$ Communications Research Centre, Ottawa, ON, Canada \\ ${ }^{2}$ Physics Department, University of New Brunswick, Fredericton, NB, Canada \\ ${ }^{3}$ University of Western Ontario, London, ON, Canada \\ ${ }^{4}$ Dept. of Physics and Astronomy, University of Calgary, AB, Canada \\ ${ }^{5}$ University of Saskatchewan, Saskatoon, SK, Canada
}

Received: 16 March 2010 - Revised: 27 May 2010 - Accepted: 1 June 2010 - Published: 21 June 2010

\begin{abstract}
High-latitude irregularities can impair the operation of GPS-based devices by causing fluctuations of GPS signal amplitude and phase, also known as scintillation. Severe scintillation events lead to losses of phase lock, which result in cycle slips. We have used data from the Canadian High Arctic Ionospheric Network (CHAIN) to measure amplitude and phase scintillation from L1 GPS signals and total electron content (TEC) from L1 and L2 GPS signals to study the relative role that various high-latitude irregularity generation mechanisms have in producing scintillation. In the first year of operation during the current solar minimum the amplitude scintillation has remained very low but events of strong phase scintillation have been observed. We have found, as expected, that auroral arc and substorm intensifications as well as cusp region dynamics are strong sources of phase scintillation and potential cycle slips. In addition, we have found clear seasonal and universal time dependencies of TEC and phase scintillation over the polar cap region. A comparison with radio instruments from the Canadian GeoSpace Monitoring (CGSM) network strongly suggests that the polar cap scintillation and TEC variations are associated with polar cap patches which we therefore infer to be main contributors to scintillation-causing irregularities in the polar cap.
\end{abstract}

Keywords. Ionosphere (Ionospheric irregularities; Polar ionosphere) - Radio science (Space and satellite communication)

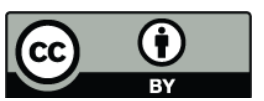

Correspondence to: P. Prikryl

(paul.prikryl@crc.gc.ca)

\section{Introduction}

The highly structured ionosphere can limit the accuracy of positions determined by the Global Positioning System (GPS) satellite navigation system and even result in a loss of carrier lock and intermittent GPS receiver operation. The auroral ionosphere is subject to space weather events which can cause significant spatial and temporal variations of electron density and density gradients resulting in highly variable total electron content (TEC) (Aarons et al., 2000) and radio scintillation, fluctuations of radio signal amplitude and phase (Aarons, 1982; Basu et al., 1998). Dependence of scintillation intensity on solar and geomagnetic activity, as well as season and local time has been recognized for many years (Aarons, 1982). Geomagnetic activity is often used as a convenient proxy to characterize the ionospheric conditions and a clear dependence of temporal and spatial variability of TEC on ionospheric activity has been demonstrated (e.g., Skone et al., 1998). Although scintillation is most intense at low latitudes (Aarons, 1982; Basu et al., 2002) it can be strong in high latitudes during disturbed conditions (Doherty et al., 2004). The high-latitude plasma structure associated with auroral and F-region polar cap patches and sun-aligned arcs is a source of scintillation that has been observed at UHF frequencies (Basu et al., 1987; MacDougall, 1990; Coker et al., 2004). Ionospheric scintillation also affects GPS receiver tracking performance (Skone, 2001). The scintillation in high latitudes has been monitored using GPS receivers (Spogli et al., 2009) and modelled using in situ data (Wernik et al., 2007) with the aim to develop climatology of scintillation at high latitudes.

Published by Copernicus Publications on behalf of the European Geosciences Union. 


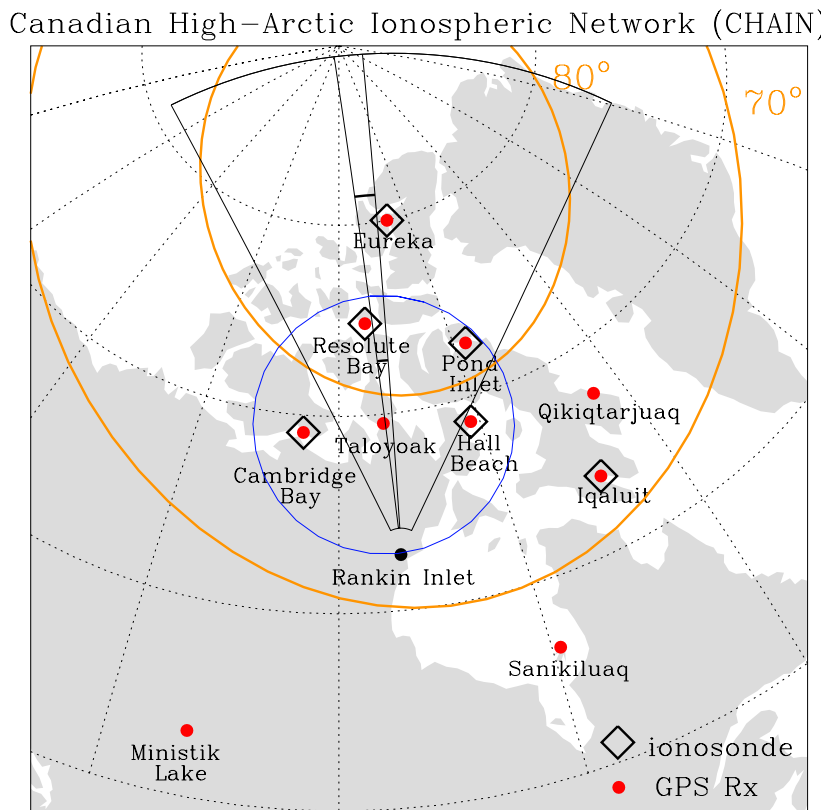

Fig. 1. Canadian High Arctic Ionospheric Network. SuperDARN Rankin Inlet radar field of view with beam 6 up to $3200 \mathrm{~km}$ range and the NORSTAR Taloyoak all-sky imager field of view are superposed. Corrected geomagnetic (CGM) latitudes $70^{\circ}$ and $80^{\circ}$ are shown.

Recently, a network of GPS receivers and ionosondes has been installed in the Canadian Arctic (Jayachandran et al., 2009) to monitor TEC and scintillation. The network is called the Canadian High Arctic Ionospheric Network (CHAIN). In this paper we describe the network, its objectives and report first results. Optical, radar and magnetometer data of the CGSM program (Liu, 2005), are used to support the scintillation data analysis from the CHAIN instruments. In-situ and radio propagation measurements with the Enhanced Polar Outflow Probe (ePOP) are planned to further our studies of scintillation in the high-latitude ionosphere.

\section{Instruments}

CHAIN is an array of ten specialized GPS receivers and six Canadian Advanced Digital Ionosondes (CADIs) (MacDougall et al., 1995) distributed from auroral oval to polar cap (Fig. 1). The collocation of six of the ten GPS receivers with ionosondes will have an added advantage in tomographic imaging of the electron density structures in the polar cap and calibration of the GPS data. Most of the collected data are transferred to the University of New Brunswick CHAIN data centre in near-real-time. The instrument locations and further details are described by Jayachandran et al. (2009; Table 1). The focus of CHAIN is on the ionospheric structure and dynamics at high temporal resolution and spatial scales from $1000 \mathrm{~km}$ down to a few kilome- ters, which affect radio propagation and cause scintillation of satellite signals. Such effects can have a detrimental impact on operation of navigation and communication systems.

The CHAIN GPS receivers are the GPS Ionospheric Scintillation and TEC monitors (GISTM) GSV 4004B (Van Dierendonck and Arbesser-Rastburg, 2004). GISTM consists of a NovAtel OEM4 dual frequency receiver with special firmware specifically configured to measure and log power and phase of the GPS L1 signal at high sampling rate $(50 \mathrm{~Hz})$. The receiver computes ionospheric TEC (total electron content) using both GPS L1 and L2 signals. GSV 4004B can also automatically compute and log the amplitude scintillation index, S4, which is the standard deviation of the received power normalized by its mean value, and the phase scintillation index $\sigma_{\phi}$, the standard deviation of the detrended phase using a filter in the receiver with $0.1 \mathrm{~Hz}$ cutoff frequency. This receiver is capable of tracking and reporting scintillation and TEC measurements simultaneously from up to 10 GPS satellites in view (Jayachandran et al., 2009).

CADIs use a receiving antenna array consisting of four dipoles arranged along the sides of a square $30-60 \mathrm{~m}$ on a side, with the centres of the four dipoles being at the centres of the four sides of a square. Each antenna is attached to a dedicated receiver thus providing interferometric measurements including angle of arrival. The CADI data are a mixture of traditional swept frequency ionograms and fixed frequency "ionograms" monitoring ionospheric echoes from a range of virtual heights. The fixed frequency is chosen so as to get the most continuous ionospheric echoes throughout the day. For polar cap observations the usual fixed frequencies are $\sim 3$ and $\sim 4 \mathrm{MHz}$. Fixed frequency observations are made every $30 \mathrm{~s}$ to track dynamic ionospheric convection at high latitudes. Ionograms (interleaved with the fixed frequency observations) are taken at less frequent intervals, typically each minute but sometimes only every $5 \mathrm{~min}$. The drift measurements use the fixed transmitter frequency mode (Grant et al., 1995). The inclusion of CADIs in CHAIN will allow us to perform more realistic 3-D tomographic inversions of the ionosphere using the Multi-Instrument Data Analysis System - MIDAS (Mitchell and Spencer, 2003) or the Global Assimilative Ionospheric Model - GAIM (Hajj et al., 2004).

The Super Dual Auroral Radar Network (SuperDARN) is a network of HF radars with look areas covering a large fraction of the high-latitude ionosphere (Greenwald et al., 1995; Chisham et al., 2007). The radars transmit at frequencies 8$20 \mathrm{MHz}$ along 16 successive azimuthal beams, each of which is gated into 75 range bins. The bins are $45 \mathrm{~km}$ long in standard operations, and the dwell time for each beam is $7 \mathrm{~s}$. A full 16-beam scan with successive beams separated by $3.25^{\circ}$ covers $52^{\circ}$ in azimuth every $2 \mathrm{~min}$. Several parameters including the line-of-sight Doppler velocity, spectral width and backscatter power from ionospheric plasma irregularities are routinely measured. The PolarDARN component of SuperDARN covers a large portion of the polar ionosphere in the Northern Hemisphere. The main objective of SuperDARN 

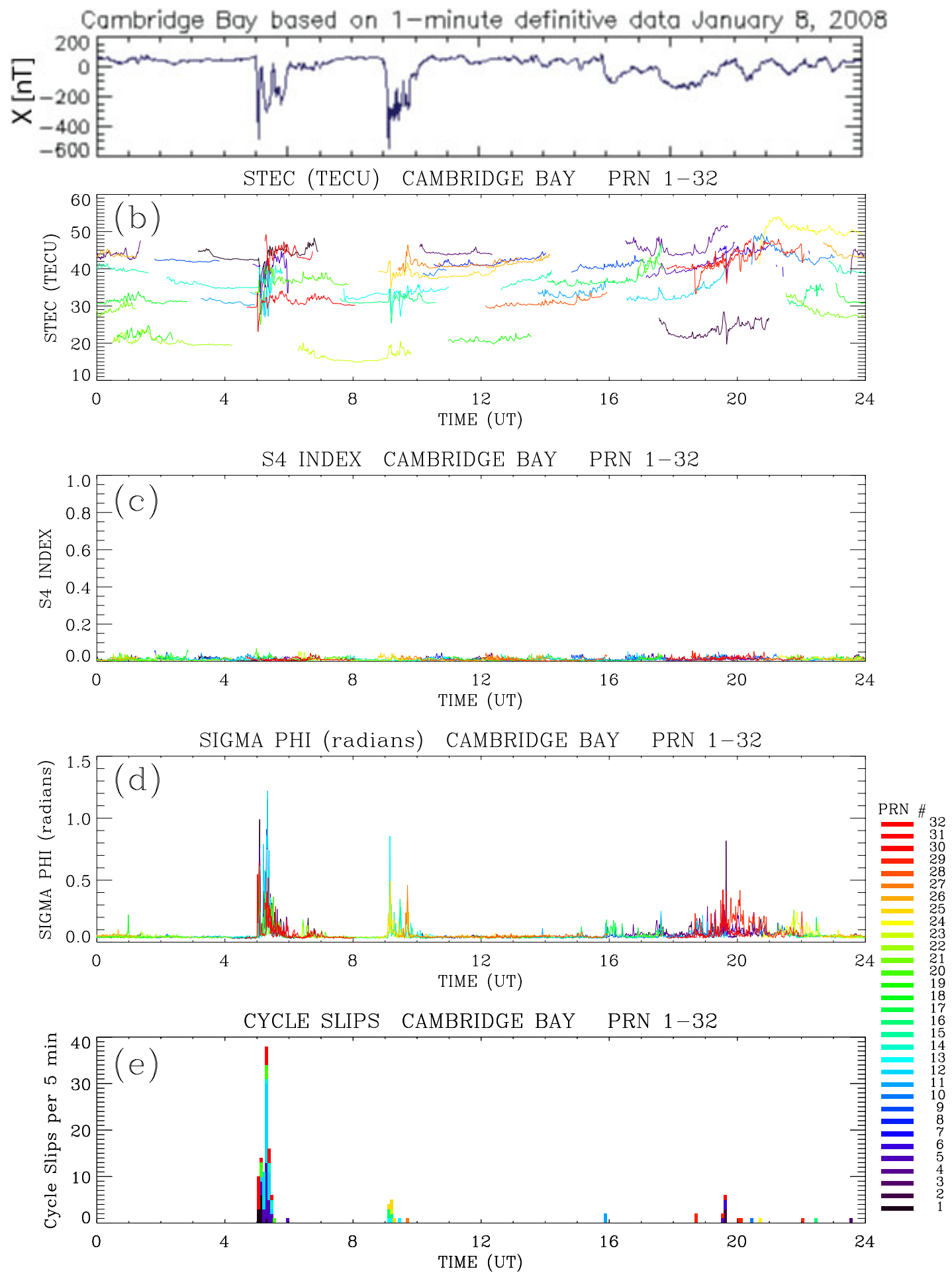

Fig. 2. (a) The magnetic field X component, (b) slant TEC, (c) S4 index, (d) phase scintillation and (e) number of cycle slips observed in Cambridge Bay.

is to study ionospheric convection (electric fields) by observing the backscatter from field-aligned irregularities that drift with $\boldsymbol{E} \times \boldsymbol{B}$. The data from one of the PolarDARN radars that is looking over Resolute Bay and Eureka from Rankin Inlet (MLAT $73.1^{\circ} \mathrm{N}$ ) is used in this study. 


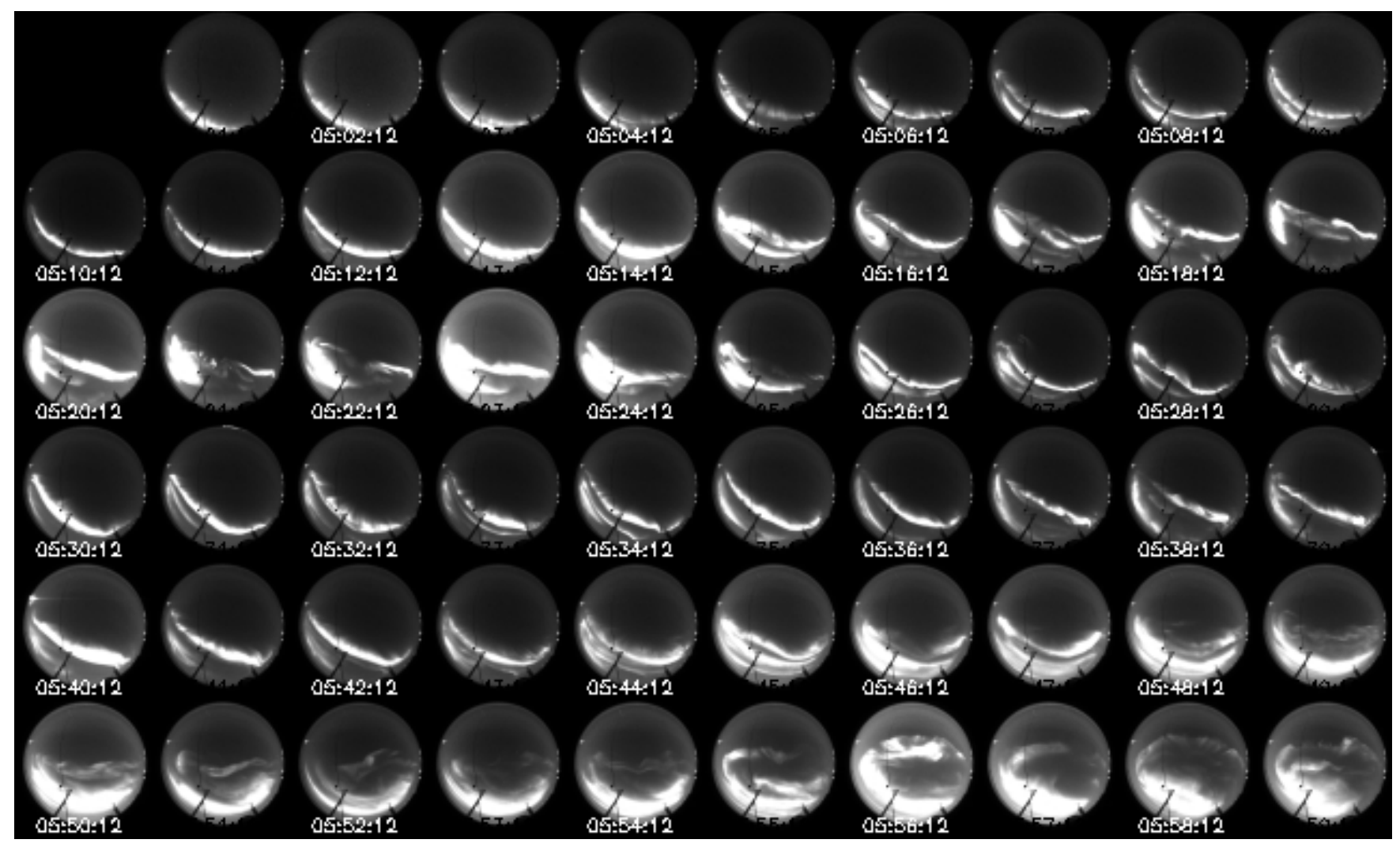

Fig. 3. Series of 557.7-nm emission all-sky images from Taloyoak between 05:00 and 06:00 UT on 8 January 2008.

The Northern Solar Terrestrial Array (NORSTAR) (Donovan et al., 2003) is an optical and radio facility designed to remotely sense auroral precipitation on a continental scale. NORSTAR consists of CCD-based All-Sky Imagers (ASIs), Meridian Scanning Photometers (MSPs), and riometers. We use data from the Taloyoak all-sky camera which collected data every $15 \mathrm{~s}$ at wavelengths of 557.7 and $630.0 \mathrm{~nm}$. Five CHAIN GPS receivers including Cambridge Bay are within the field of view of the all-sky camera in Taloyoak.

\section{GPS scintillation in the auroral and cusp regions}

During the current deep solar minimum the auroral oval has remained at rather high latitudes so that the CHAIN instruments sample both the auroral oval and polar cap. The GPS receiver in Cambridge Bay was installed and running continuously from December 2007. On the moderately disturbed day of 8 January 2008 (maximum 3-h Kp was 4-), Cambridge Bay was at the poleward edge of auroral oval, as extrapolated from, e.g., particle measurements on the NOAA POES satellite (http://www.swpc.noaa.gov/pmap/), or from DMSP satellite particle fluxes (Newell et al., 2002) (http: //sd-www.jhuapl.edu/Aurora/ovation/).

The magnetometer in Cambridge Bay observed auroral substorm intensifications at 05:00 and just after 09:00 UT and disturbed conditions on the dayside after 13:00 UT. Figure 2a shows the magnetic field X-component. Associated with the geomagnetic perturbations were enhancements of slant TEC variations and of phase scintillation measured by the GPS receiver in Cambridge Bay, as shown in Fig. $2 b$ and $2 \mathrm{~d}$. For the GPS results, only values for elevations above $30^{\circ}$ are shown. While the amplitude scintillation (S4 index) remained low (Fig. 2c), there was significant phase scintillation, represented by $\sigma_{\phi}$ values (defined in Sect. 2). These results indicate what has been known for some time: at high latitudes, GPS scintillation monitors often detect high phase scintillation in the presence of low amplitude scintillation. Numerous cycle slips were observed, particularly during the two substorm events and in the cusp just before 20:00 UT during the times when $\sigma_{\phi}$ values exceeded 0.5 radians (Fig. 2e). A cycle slip (Horvath and Crozier, 2007) is defined here as a jump in differential phase TEC of more than or equal to 1.5 TECU in one second (1 TEC Unit corresponds to $10^{16}$ electrons $/ \mathrm{m}^{2}$ ). The satellites are identified by the receiver by means of pseudo random noise (PRN) numbers (1-32; coded by color in Fig. 2).

The phase scintillation and cycle slips were associated with enhanced auroral activity. A decimated series of 557.7$\mathrm{nm}$ emission images in Fig. 3 show an auroral arc brightening and evolving into a swirl (vortex) at one point. In Fig. 4, 


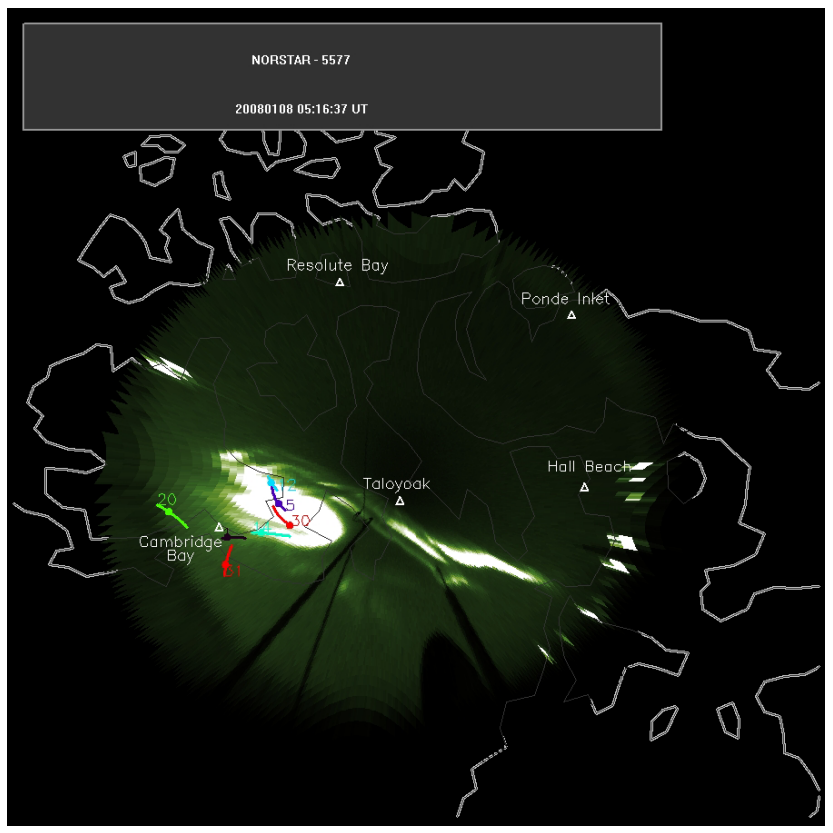

Fig. 4. The 557.7-nm image from 8 January 2008, 05:16:37 UT mapped on a geographic grid assuming altitude of $110 \mathrm{~km}$. The IPPs of GPS satellites (PRN numbers) for which cycle slips were observed are superposed for one hour starting at 05:00 UT. The dots show IPPs at the time when the image was taken. The PRNs are numbered and color coded as in Fig. 2.

one of the images (05:16:37 UT) is mapped on a geographic grid with the ionospheric pierce points (IPPs) for seven GPS satellites superposed on the image assuming $110 \mathrm{~km}$ altitude. Auroral emission indicates where the energetic electron precipitation deposits most of its energy, causing an increase and sharp change in ionization and thus enhancement of TEC, phase scintillation and cycle slips. Because of this, only the IPPs for GPS satellites that detected cycle slips and phase scintillation during one hour starting at 05:00 UT are shown. They are clustered within and around the bright auroral swirl.

Another region where phase scintillation is often enhanced and cycle slip events occur is the ionospheric footprint of the cusp/cleft. The spectral width and line-of-sight velocity observed by the Prince George SuperDARN over Cambridge Bay on 8 January 2008 were particularly enhanced between 19:25 and 20:30 UT, which is typical of the HF backscatter in the cusp (Baker et al., 1995). The SuperDARN convection maps showed intense and dynamic dayside ionospheric convection from 16:00 to 22:00 UT (http://superdarn.jhuapl.edu) when the phase scintillation at Cambridge Bay was enhanced (Fig. 2d) although only a few cycle slips were detected and low S4 index values were observed at these times.

Figure 5 shows the total number of cycle slip events per month and each UT hour in 2008. Data for months from the same year are plotted from July to May (no data were recorded in June) to conform with the graphical presentation

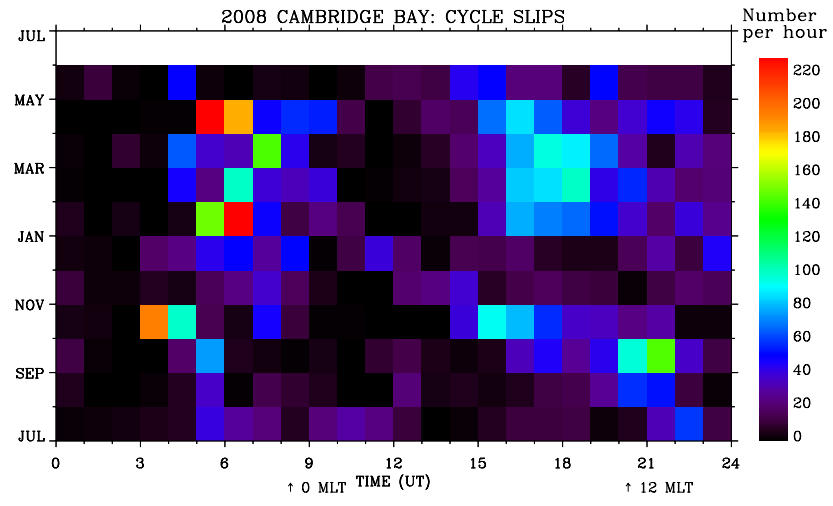

Fig. 5. The occurrence of cycle slips observed at Cambridge Bay in 2008. The arrows indicate magnetic local midnight and noon.

of seasonal and UT patterns in GPS TEC and scintillation as well as radar backscatter occurrence discussed in this paper. Prior to local magnetic midnight, the statistics show big numbers of cycle slips, which are mostly due to auroral arcs. Numerous cycle slips are observed also in the dayside ionosphere prior to or around local magnetic noon. These are caused by cusp-related activity over Cambridge Bay. There is a possibility that patches formed in the cusp and convected towards the night-time auroral oval also contribute to scintillation and cycle slips. The asymmetry of the polar cap patches distribution around magnetic midnight has been recently discussed by Moen et al. (2008). Regions of most frequent occurrence of scintillation as a function of magnetic latitude and magnetic local time (MLT) are subject of ongoing investigation to be presented in the future publication.

\section{GPS scintillation in the polar cap}

In the polar cap the sources of ionospheric structure are polar patches and sun-aligned arcs. In general, the morphology of the polar ionosphere is determined by the interplanetary magnetic field (IMF) (Carlson, 1994). For southward IMF $\left(B_{\mathrm{Z}}<0\right)$, mesoscale $(100-1000 \mathrm{~km})$ plasma density enhancements known as polar patches are produced in the dayside ionosphere near the magnetospheric cusp footprint. The patches then convect antisunward in the polar cap where they can be observed by various techniques, principally radio, optical and in situ by satellites (Weber et al., 1984). Under the condition of northward IMF $\left(B_{\mathrm{Z}}>0\right)$, the polar ionosphere is characterized by considerably different plasma convection structure and magnetospheric topology that result in sun-aligned polar arcs (Carlson, 2009). The sun-aligned or transpolar arcs delineate the polar cap plasma flow gradients/shears and provide valuable insight into magnetospheric topology and solar wind coupling processes (Carlson, 1994). Although it can be said that the polar ionosphere alternates between the two states depending on the IMF orientation, 


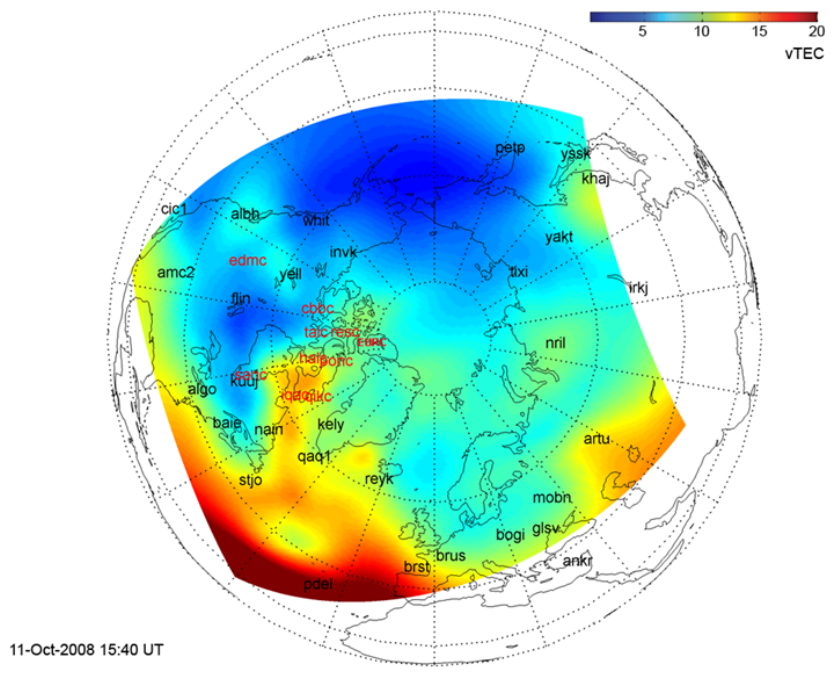

Fig. 6. Vertical TEC map showing a tongue of ionization and patches convected into the polar cap.

when the IMF $B_{\mathrm{Z}}$ switches sign often, both patches and sunaligned arcs may coexist in the polar cap at any given time. However, it is expected that patches are distorted and further structured by a variable magnetospheric electric field mapping to the ionosphere. Some of this structure would result in scintillation.

Figure 6 shows a vertical TEC map reconstructed from available GPS monitors. CHAIN stations (shown in red letters) significantly contribute to resolve some detail in a tongue of ionization (TOI) that is extended into the polar cap and fragmented into polar patches. Vertical TEC is obtained by integrating the tomographic 3-dimensional density distribution. The Weimer model (Weimer, 1995) is used to set up a Kalman filter to project tomographic images forward in time into the areas where GPS receivers are sparsely distributed (Spencer and Mitchell, 2007).

Buchau et al. (1985) showed the importance of the offset of the magnetic and geographic poles in the patch morphology. As the cusp footprint is displaced in longitude due to the rotation of the Earth, the observed occurrence frequency of patches depends both on the season and UT (Coley and Heelis, 1998). Sojka et al. (1994) simulated the formation of TOI and transport of patches using a time dependent ionospheric model (TDIM) that predicts the seasonal and UT dependence of the patch-to-background ratio of the $F_{2}$ layer maximum electron density ( $N m \mathrm{~F} 2)$. The TEC measurements reflect the total of the solar UV background electron density and the enhanced densities due to patches which in turn are a source of scintillation-causing irregularities.

Such irregularity dependences on season and UT are observed in CHAIN data. We use the Resolute Bay GPS data from 2008-2009 to represent the polar cap TEC and phase scintillation during solar minimum. The slant TEC measurements can be approximately mapped to vertical TEC

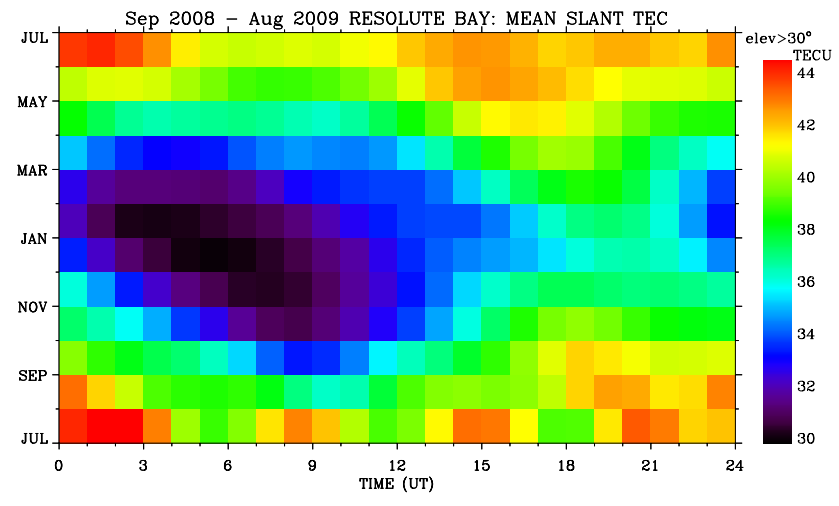

Fig. 7. The mean slant TEC derived from GPS data for Resolute Bay from September 2008 to August 2009. Magnetic local midnight and noon at Resolute Bay occur around 07:10 and 19:40 UT, respectively.

values assuming a given IPP altitude, e.g., $350 \mathrm{~km}$. Birch et al. (2002) and Mushini et al. (2009) showed that the ionospheric effective height used in the oblique-to-zenithal thin shell conversion is considerably greater or smaller than $350 \mathrm{~km}$, and using a fixed shell height results in significant errors. Also there is a bias introduced into the vertical TEC from mapping slant TEC from low elevation satellites due to the curvature of the earth. Therefore, we used slant TEC (STEC) values only down to $30^{\circ}$ elevation cutoff. Figure 7 shows STEC monthly averages for each UT hour. Data for months from September 2008 to August 2009 are plotted from July to June to conform with the graphical presentation of seasonal and UT patterns for polar patches introduced by Sojka et al. (1994). The mean values are further smoothed using a $3 \times 3$ pixel window to remove elevation dependencies due to skewed distributions of elevation angles for each hour and month caused by precession of GPS satellite orbits.

At least qualitatively, the mean STEC values show the expected seasonal and UT variation of electron density at high latitudes: elevated density in summer months due to increased solar illumination and a diurnal variation maximizing around winter solstice due to the offset of the magnetic and geographic poles. The deep minimum in plasma density during winter months corresponds to times when the cusp is located in darkness at magnetic longitudes around $100^{\circ} \mathrm{E}$. As mentioned earlier, once the CHAIN data are available and analyzed for all stations, mean STEC values and scintillation occurrence will be mapped as a function of MLAT and MLT.

While the S4 index computed for Resolute Bay has remained very low, enhancements of phase scintillation are observed even during solar minimum. Figure 8 shows monthly averages of $\sigma_{\phi}$ for each UT hour. Similarly to TEC (Fig. 7), the phase scintillation is low when the patch plasma density is expected to be low, particularly in winter before about 12:00 UT. However, the mean $\sigma_{\phi}$ is higher than average near the magnetic noon, particularly from April to November 


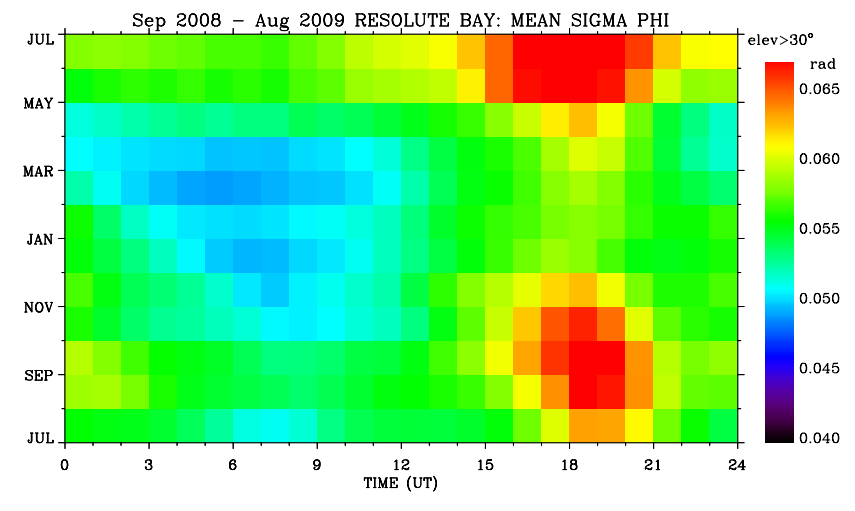

Fig. 8. The average $\sigma_{\phi}$ for Resolute Bay from September 2008 to August 2009. Magnetic local midnight and noon at Resolute Bay occur around 07:10 and 19:40 UT, respectively.

when TEC is also elevated and the cusp ionosphere is expected to be highly structured by variable electric fields (Shepherd et al., 2003).

\section{F-region irregularities in the polar cap}

The role of patches in structuring the ionosphere is further investigated using statistical analysis of HF radar backscatter in the polar cap. At auroral latitudes, a case study by Milan et al. (2005) showed a close correspondence between the 250-MHz scintillation and the HF radar backscatter power. In the polar cap, such close relationship between scintillation and HF backscatter remains to be demonstrated. Large-scale plasma structures in high latitudes that include polar cap patches, boundary blobs, sun-aligned arcs and density depletions are a source of small-scale irregularities produced by the gradient-drift instability and other mechanisms (Tsunoda, 1988) that are responsible for HF radar backscatter due to decameter field-aligned irregularities. The large-scale structures are expected to be spatially collocated with kilometer size irregularities causing radio scintillation.

Ionospheric backscatter obtained by the PolarDARN radar in Rankin Inlet indicates the presence of the F-region decameter irregularities in the polar cap. The occurrence frequency of ionospheric backscatter is obtained for beam 6 at ranges between 1200 and $2200 \mathrm{~km}$ (Fig. 1) by counting the number of range bins with F-region ionospheric scatter over Resolute Bay and Eureka. Figure 9 shows the seasonal and UT dependence of the radar backscatter occurrence by binning the statistics for each month into one-hour intervals. The seasonal and UT patterns are very similar to the patch-to-background ratio modeled by Sojka et al. (1994; their Plate 4). This similarity is a strong indication that the F-region ionospheric backscatter is mainly due to polar patches, implying that patches are a primary source of Fregion irregularities in the polar cap.

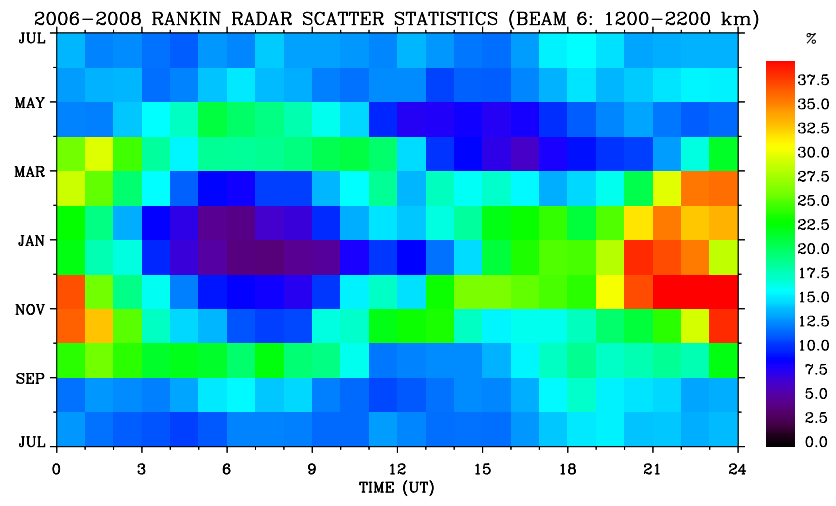

Fig. 9. The F-region backscatter statistics for the Rankin Inlet radar beam 6. Magnetic local midnight and noon for a point midway between Resolute Bay and Eureka (mid-beam 6) at altitude $350 \mathrm{~km}$ are approximately at 06:50 and 19:20 UT, respectively.

\section{F-region ionosonde echoes from Resolute Bay}

Polar patches are routinely observed by CADI in Resolute Bay. In the fixed-frequency ionograms they appear as Ushaped structures separated by troughs (James and MacDougall, 1997). The amount of ionospheric echoes obtained from the fixed-frequency sounding at virtual heights above $200 \mathrm{~km}$ is a measure of the F-region ionization and its structure. The number of echoes increases when the echoes come from a wider range of virtual heights, implying enhanced ionospheric structure, namely patches separated by deep troughs. Excluding virtual heights below $200 \mathrm{~km}$, the contribution due to high-energy precipitation in sun-aligned arcs is partly eliminated.

Time series of the F-region echo occurrence frequency, namely the number of scattering points above $200 \mathrm{~km}$ with received signal exceeding relative power of $5 \mathrm{~dB}$, are binned into one-hour intervals and averaged for each month. The noise/interference periods that are manifested by echoes spanning the full range of virtual heights at a given time are discarded. Figure 10 shows the F-region echo statistics for CADI in Resolute Bay from August 2006 to May 2009. The monthly means of hourly occurrence of F-region echoes clearly depends on the season and UT. For the summer solstice months of June-July there is a deep minimum around 18:00 UT and a moderate increase in echoes before 12:00 UT. The diurnal variation reverses phase near the winter solstice (late autumn and early winter) with a minimum in the echo occurrence between about 06:00 and 12:00 UT and a maximum between 18:00 and 23:00 UT. Near the equinoxes the number of echoes maximizes before 12:00 UT (particularly for the spring equinox months) and is reduced after 12:00 UT.

As for F-region radar backscatter (Fig. 9), the seasonal pattern of the F-region ionosonde echo statistics (Fig. 10) is similar to modeling results of the patch-to-background ratio as a 


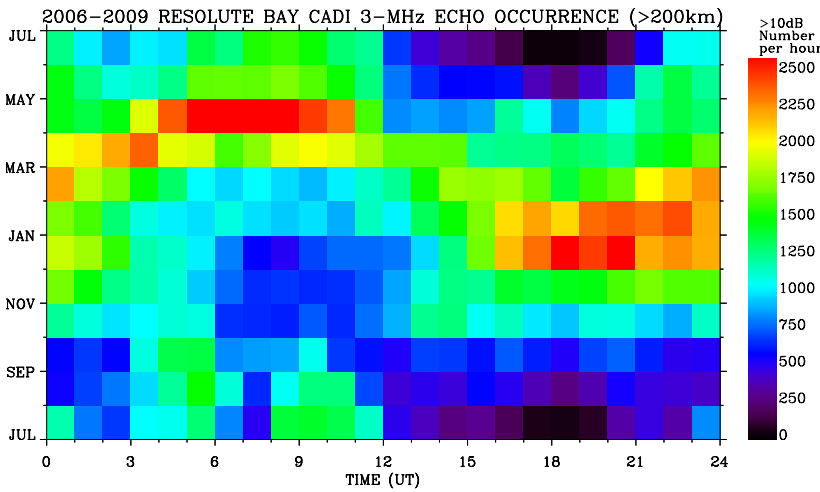

Fig. 10. The 2006-2009 statistics of F-region echoes for CADI in Resolute Bay. Magnetic local midnight and noon at Resolute Bay occur around 07:10 and 19:40UT, respectively.

function of UT and season (Sojka et al., 1994), which were already found consistent with earlier observations (Buchau et al., 1985) of the patch diurnal effect based on digisonde measurements from Thule, Greenland ( $86^{\circ}$ CGM latitude). At only $3^{\circ}$ lower CGM latitude in Resolute Bay, CADI echo statistics further supports the modeling results. This is not surprising because the steeper the density gradients or the patch-to-background ratios, the more CADI returns are received. In other words, the echoes are not only from the bottom side of the F-region as they would be for a horizontal unstructured ionospheric layer but also from U-shaped walls of the patches as they pass overhead. It should be noted that the modeling result by Sojka et al. (1994) was for the patch-tobackground ratio in a region between 23:00 and 01:00 MLT and $80^{\circ}$ magnetic latitude, i.e., for all longitudes and a fixed MLT. This is equivalent to considering a fixed longitude and stepping through UT hours, because any geographic location rotates under such an MLT-defined region in $24 \mathrm{~h}$. Since the high-latitude locations like Thule and Resolute Bay lie close to the magnetic pole, the statistical distributions of Sojka et al. should apply to all such stations.

\section{Summary}

The first year of CHAIN operation coincided with the deep solar minimum of 2008-2009. While the S4 index remained very low, events of strong phase scintillation were observed and accompanied with numerous cycle slips. In the night time auroral oval, cycle slips were associated with auroral arc brightenings and auroral substorms. In the polar cap, the seasonal and hourly dependencies of the occurrence of the fixed-frequency ionosonde F-region echoes and the HF radar backscatter were very similar, and in general agreed with model dependencies of the patch-to-background $N m \mathrm{~F} 2$ ratio by Sojka et al. (1994). These results indicate that, in the polar cap, the F-region ionosonde echoes and radar backscatter from field-aligned ionospheric irregularities are primar- ily associated with polar cap patches. The mean TEC and phase scintillation index show seasonal and hourly dependencies which are similar to those for patches, except for summer months, when TEC and phase scintillation are enhanced. These enhancements are due to a tongue of ionization extending into the polar cap across the cusp/cleft region, where the plasma is structured.

\section{Future work: TEC and scintillation measurements with ePOP}

In the near future, scintillation studies will be supported by instruments on the Enhanced Polar Outflow Probe (ePOP) (Yau et al., 2006). The Coherent EM Radiation Tomography experiment (CERTO) consists of a tri-frequency beacon broadcasting at three radio (VHF-UHF) frequencies to measure TEC and scintillation in conjunction with arrays of ground receivers and to reconstruct tomographic images of the ionosphere. The occultation of GPS signals received by the GPS attitude/profiling (GAP) instrument will provide an additional tomographic tool to observe the ionospheric structure. The Radio Receiver Instrument (RRI) in conjunction with ground facilities such as EISCAT, SuperDARN and CHAIN will provide a new perspective to study the radio wave propagation in the F-region and topside ionosphere, in particular the 3-dimensional structures of ionospheric irregularities. In addition, high resolution in situ measurements of ionospheric plasma density spectra will be used in the scintillation modeling (Wernik et al., 2007). It is planned to compare modeled and observed scintillation climatologies in high latitudes using the ePOP in situ measurements and CHAIN scintillation data, respectively.

Acknowledgements. Infrastructure funding for CHAIN was provided by the Canada Foundation for Innovation and the New Brunswick Innovation Foundation. CHAIN and CGSM operation is conducted in collaboration with the Canadian Space Agency (CSA). The funding for the operation of PolarDARN radars was provided by the Natural Sciences and Engineering Research Council of Canada (NSERC) and CSA.

Topical Editor K. Kauristie thanks L. Alfonsi and another anonymous referee for their help in evaluating this paper.

\section{References}

Aarons, J.: Global morphology of ionospheric scintillations, Proceedings of IEE, 70(4), 360-378, 1982.

Aarons, J., Lin, B., Mendillo, M., Liou, K., and Codrescu, M.: Global Positioning System phase fluctuations and ultraviolet images from the Polar satellite, J. Geophys. Res., 105, 5201-5213, 2000.

Baker, K. B., Dudeney, J. R., Greenwald, R. A., Pinnock, M., Newell, P. T., Rodger, A. S., Mattin, N., and Meng, C.-I.: HF radar signatures of the cusp and low-latitude boundary layer, J. Geophys. Res., 100, 7671-7695, 1995. 
Basu, S., MacKenzie, E. M., Basu Su., Costa, E., Fougere, P. F., Carson Jr., H. C., and Whitney, H. E.: $250 \mathrm{MHz} / \mathrm{GHz}$ scintillation parameters in the equatorial, polar, and auroral environments, IEEE Journal on Selected Areas in Communications, SAC-2(2), 102-115, 1987.

Basu, S., Weber, E. J., Bullett, T. W., Keskinen, M. J., MacKenzie, E., Doherty, P., Sheehan, R., Kuenzler, H., Ning, P., and Bongiolatti, J.: Characteristics of plasma structuring in the cusp/cleft region at Svalbard, Radio Sci., 33, 1885-1899, 1998.

Basu, S., Groves, K. M., Basu, Su., and Sultan, P. J.: Specification and forecasting of scintillations in communication/navigation links: current status and future plans, J. Atmos. Solar-Terr. Phys., 64(16), 1745-1754, 2002.

Birch, M. J., Hargreaves, J. K., and Bailey, G. J.: On the use of an effective ionospheric height in electron content measurement by GPS reception, Radio Sci., 37(1), 1015, doi:10.1029/2000RS002601, 2002.

Buchau, J., Weber, E. J., Anderson, D. N., Carlson Jr., H. C., Moore, J. G., Reinisch, B. W., and Livingston, R. C.: Ionospheric structures in the polar cap: Their origin and relation to $250 \mathrm{MHz}$ scintillation, Radio Science, 20(3), 325-338, 1985.

Carlson Jr., H. C.: Dark polar ionosphere: Progress and future challenges, Radio Sci., 29(1), 157-165, 1994.

Carlson, H. C.: Characterizing the polar-cap ionosphere, in: Characterising the ionosphere, edited by: Wyman, G.; Technical Report RTO-TR-IST-051, Chapter 1, pp. 70-87. Neuilly-sur-Seine, France: RTO, http://www.rto.nato.int/abstracts.aspx, 2009.

Chisham, G., Lester, M., Milan, S. E., Freeman, M. P., Bristow, W. A., Grocott, A., McWilliams, K. A., Ruohoniemi, J. M., Yeoman, T. K., Dyson, P. L., Greenwald, R. A., Kikuchi, T., Pinnock, M., Rash, J. P. S., Sato, N., Sofko, G. J., Villain J.-P., and Walker, A. D. M.: A decade of the Super Dual Auroral Radar Network (SuperDARN): Scientific achievements, new techniques and future directions, Surv. Geophys, 28, 33-109, doi:10.1007/s10712-0079017-8, 2007.

Coker, C., Bust, G. S., Doe, R. A., and Gaussiran II, T. L.: High-latitude plasma structure and scintillation, Radio Sci., 39, RS1S15, doi:10.1029/2002RS002833, 2004.

Coley, W. R. and Heelis, R. A.: Structure and occurrence of polar ionization patches, J. Geophys. Res., 103(A2), 2201-2208, 1998.

Doherty, P. H., Delay, S. H., Valladares, C. E., and Klobuchar, J. A.: Ionospheric scintillation effects on GPS in the equatorial and auroral regions, Journal of the Institute of Navigation, 50(4), 235245, 2004.

Donovan, E., Trondsen, T., Cogger, L., and Jackel, B.: Auroral imaging within the Canadian CANOPUS and NORSTAR projects, Sodankylä Geophysical Observatory Publications, 92, 109-112, 2003.

Grant, I. F., MacDougall, J. W., Ruohoniemi, J. M., Bristow, W. A., Sofko, G. J., Koehler, J. A., Danskin, D., and André D.: Comparison of plasma flow velocities determined by the ionosonde Doppler drift technique, SuperDARN radars, and patch motion, Radio Sci., 30, 1537-1549, 1995.

Greenwald, R. A., Baker, K. B., Dudeney, J. R., Pinnock, M., Jones, T. B., Thomas, E. C., Villain, J.-P., Cerrisier, J.-C., Senior, C., Hanuise, C., Hunsucker, R. D., Sofko, G., Koehler, J., Nielsen, E., Pellinen, R., Walker, A.D.M., Sato, N., and Yamagishi, H.: DARN/ SUPERDARN A global view of the dynamics of highlatitude convection, Space Sci. Rev., 71, 761-796, 1995.
Hajj, G. A., Wilson, B. D., Wang, C., Pi, X., and Rosen, I. G.: Data assimilation of ground GPS total electron content into a physicsbased ionospheric model by use of the Kalman filter, Radio Sci., 39, RS1S05, doi:10.1029/2002RS002859, 2004.

Horvath, I. and Crozier, S.: Software developed for obtaining GPSderived total electron content values, Radio Sci., 42, RS2002, doi:10.1029/2006RS003452, 2007.

James, H. G. and MacDougall, J. W.: Signatures of polar cap patches in ground ionosonde data, Radio Sci., 32(2), 497-513, 1997.

Jayachandran, P. T., Langley, R. B., MacDougall, J. W., Mushini, S. C., Pokhotelov, D., Hamza, A. M., Mann, I. R., Milling, D. K., Kale, Z. C., Chadwick, R., Kelly, T., Danskin, D. W., and Carrano, C. S.: Canadian High Arctic Ionospheric Network (CHAIN), Radio Sci., 44, RS0A03, doi:10.1029/2008RS004046, 2009.

Liu, W. W.: Canadian space environment program and international living with a star, Adv. Space Res., 35(1), 51-60, 2005.

MacDougall, J. W.: The polar-cap scintillation zone, J. Geomag. Geoelectr., 42, 777-788, 1990.

MacDougall, J. W., Grant, I. F., and Shen, X.: The Canadian Advanced Digital Ionosonde: Design and results, in: Report UAG14: Ionospheric Networks and Stations, World Data Center A for Solar-Terrestrial Physics, 21, 1995.

Milan, S. E., Basu, S., Yeoman, T. K., and Sheehan, R. E.: A comparison of satellite scintillation measurements with HF radar backscatter characteristics, Ann. Geophys., 23, 3451-3455, 2005 , http://www.ann-geophys.net/23/3451/2005/.

Mitchell, C. N. and Spencer, P. S. J.: A three dimensional timedependent algorithm for ionospheric imaging using GPS signals, Annals of Geophysics, 46, 687-696, 2003.

Moen, J., Qiu, X. C., Carlson, H. C., Fujii, R., and McCrea, I. W.: On the diurnal variability in F2-region plasma density above the EISCAT Svalbard radar, Ann. Geophys., 26, 2427-2433, 2008, http://www.ann-geophys.net/26/2427/2008/.

Mushini, S. C., Jayachandran, P. T., Langley, R. B., and MacDougall, J. W.: Use of varying shell heights derived from ionosonde data in calculating vertical total electron content (TEC) using GPS - New method, J. Adv. Space Res., 44(11), 1309-1313, doi:10.1016/j.asr.2009.07.015, 2009.

Newell, P. T., Sotirelis, T., Ruohoniemi, J. M., Carbary, J. F., Liou, K., Skura, J. P., Meng, C.-I., Deehr, C., Wilkinson, D., and Rich, F. J.: OVATION: Oval variation, assessment, tracking, intensity, and online nowcasting, Ann. Geophys., 20, 1039-1047, 2002, http://www.ann-geophys.net/20/1039/2002/.

Shepherd, S. G., Ruohoniemi, J. M., and Greenwald, R. A.: Direct measurements of the ionospheric convection variability near the cusp/throat, Geophys. Res. Lett., 30(21), 2109, doi:10.1029/ 2003GL017668, 2003.

Skone, S. and Cannon, M. E.: Auroral zone ionospheric considerations for WADGPS, J. of the Institute of Navigation, 45(2), 117-128, 1998.

Skone, S. H.: The impact of magnetic storms on GPS receiver performance, J. Geodesy, 75, 457-468, 2001.

Sojka, J. J., Bowline, M. D., and Schunk, R. W.: Patches in the polar-cap ionosphere: UT and seasonal dependence, J. Geophys. Res., 99, 14959-14970, 1994.

Spencer, P. S. J. and Mitchell, C. N.: Imaging of fast moving 
electron-density structures in the polar cap, Annals of Geophysics, 50(3), 427-434, 2007.

Spogli, L., Alfonsi, L., De Franceschi, G., Romano, V., Aquino, M. H. O., and Dodson, A.: Climatology of GPS ionospheric scintillations over high and mid-latitude European regions, Ann. Geophys., 27, 3429-3437, 2009,

http://www.ann-geophys.net/27/3429/2009/.

Tsunoda, R. T.: High-latitude F region irregularities - A review and synthesis, Rev. Geophys., 26, 719-760, 1988.

Van Dierendonck, A. J. and Arbesser-Rastburg, B.: Measuring ionospheric scintillation in the equatorial region over Africa, including measurements from SBAS geostationary satellite signals, Proceedings of ION GNSS 17th technical meeting of the satellite division, Long Beach, CA, 316, 2004.
Weber, E. J., Buchau, J., Moore, J. G., Sharber, J. R., Livingston, R. C., Winningham, J. D., and Reinisch, B. W.: F-layer ionization patches in the polar cap, J. Geophys. Res., 90(A7), 1683-1694, 1984.

Weimer, D. R.: Models of high-latitude electric potentials derived with a least error fit of spherical harmonic coefficients, J. Geophys. Res. Space Phys., 100, 19595-19607, 1995.

Wernik, A. W., Alfonsi, L., and Materassi, M.: Scintillation modeling using in situ data, Radio Sci., 42, RS1002, doi:10.1029/2006RS003512, 2007.

Yau, A. W., James, H. G., and Liu, W.: The Canadian Enhanced Polar Outflow Probe (e-POP) mission in ILWS, Adv. Space Res., 38(8), 1870-1877, 2006. 